\title{
Erratum: Secure Conversation Using Cryptographic Algorithms in 3G Mobile Communication
}

\author{
Alpesh R. Sankaliya, V. Mishra, and Abhilash Mandloi \\ Department of Electronics \\ Sardar Vallabhbhai National Institute of Technology, Surat-395007 \\ Gujarat, India \\ alpeshrs@yahoo.com, vive@eced.svnit.ac.in, asm@eced.svnit.ac.in
}

D.C. Wyld et al. (Eds.): NeCoM/WeST/WiMoN 2011, CCIS 197, pp. 396-406, 2011.

(C) Springer-Verlag Berlin Heidelberg 2011

DOI 10.1007/978-3-642-22543-7_76

Due to a serious case of plagiarism this paper has been retracted.

The paper "Secure Conversation Using Cryptographic Algorithms in 3G Mobile Communication" authored by Alpesh R. Sankaliya, V. Mishra, and Abhilash Mandloi, DOI 10.1007/978-3-642-22543-7_40, appearing on pages 396-406 of this publication has been retracted due to a severe case of plagiarism. It is a plagiarized version of the paper "Implementation of Cryptographic Algorithms for GSM Cellular Standard", authored by Alpesh R. Sankaliya, V.Mishra and Abhilash Mandloi, published in Ganpat University Journal of Engineering \& Technology, vol. 1, issue 1 at http://academicpublishingplatforms.com/search-article.php?journal=GNUJET\&number=1\& article $=696$. 